Buletin Ilmiah Math. Stat. dan Terapannya (Bimaster)

Volume 08, No. 4 (2019), hal 667 - 674.

\title{
MODEL VECTOR AUTOREGRESSIVE EXOGENOUS (VARX) DALAM MEMPREDIKSI HASIL PRODUKSI KARET PTPN XIII PROVINSI KALIMANTAN BARAT
}

\author{
Rosella Alifa El Vinie, Shantika Martha, Setyo Wira Rizki
}

\begin{abstract}
INTISARI
Model Vector Autoregressive Exogenous (VARX) dapat digunakan untuk memprediksi data deret waktu lebih dari satu variabel yang menggunakan variabel eksogen dalam sistem persamaannya. Model VARX menggunakan variabel endogen yang saling berhubungan dipengaruhi waktu sebelumnya dan terdapat variabel eksogen yang mempengaruhi variabel endogen tersebut. Penelitian ini menggunakan data sekunder, yaitu data bulanan deret waktu hasil produksi karet kering dan karet basah dalam periode tahun 2016 sampai tahun 2018 pada kebun Sintang di Kalimantan Barat serta data deret waktu curah hujan pada kebun. Tujuan penelitian ini adalah melakukan pemodelan dan memprediksi hasil produksi karet kering dan karet basah PTPN XIII pada periode Juli sampai Desember 2018 dengan model VARX. Hasil analisis menunjukkan bahwa model VARX yang dapat diterapkan terhadap data hasil produksi karet kering dan karet basah adalah VARX(1,1). Nilai MAPE untuk model VARX $(1,1)$ pada masing-masing variabel yaitu 14,73\% dan 16,06\% sehingga ketepatan hasil prediksi model dapat dikatakan baik.
\end{abstract}

Kata Kunci: karet basah, karet kering, curah hujan, MAPE

\section{PENDAHULUAN}

Karet merupakan salah satu komoditas pertanian yang penting untuk Indonesia dan lingkup internasional karena banyak menunjang perekonomian negara. Sebagian besar perkebunan karet di Indonesia merupakan perkebunan rakyat. Terdapat beberapa macam karet salah satunya yaitu bahan olah karet yang terdiri dari lateks kebun serta gumpalan lateks kebun yang diperoleh dari pohon karet.

Lateks kebun atau karet basah merupakan cairan getah yang dihasilkan dari proses penyadapan pohon karet dan belum mengalami pengolahan. Karet basah mengandung padatan karet per satuan berat yang dihitung dalam satuan persen yang disebut Kadar Karet Kering (KKK) dimana dalam penentuan kadarnya yaitu dengan memisahkan padatan dari lateks dengan cara pembekuan, pencucian dan pengeringan. Kadar karet kering pada lateks dipengaruhi beberapa faktor yaitu umur pohon, musim, suhu dan jenis klon [1].

Produksi karet tentunya dipengaruhi oleh banyak faktor di antaranya yang berpengaruh signifikan adalah curah hujan, luas lahan, tenaga kerja, pemupukan, pohon per hektar, jumlah pohon dan harga pokok. Curah hujan juga merupakan faktor penentu terpenuhinya ketersediaan air bagi tanaman karet dimana jumlah air dapat memberikan dampak bagi produktivitas karet [2].

Perlunya dilakukan peramalan produksi karet bertujuan agar pemerintah dapat menentukan biaya operasional, penentuan harga jual dan banyaknya produksi karet yang dihasilkan [3]. Untuk memprediksi lebih dari satu variabel produksi karet di PTPN XIII provinsi Kalimantan Barat dapat digunakan suatu analisis statistika yaitu analisis runtun waktu multivariat. Ada beberapa model analisis runtun waktu multivariat salah satunya yaitu Vector Autoregressive Exogenous (VARX).

Model VARX merupakan model deret waktu untuk memodelkan beberapa variabel endogen yang saling berhubungan dipengaruhi waktu sebelumnya dan terdapat variabel eksogen yang mempengaruhi variabel endogen tersebut [4]. Pada penelitian ini, model VARX digunakan dalam prediksi hasil produksi karet di PTPN XIII provinsi Kalimantan Barat dengan variabel hasil produksi karet basah dan karet kering sebagai variabel endogen dan variabel curah hujan sebagai variabel eksogen. 


\section{ANALISIS DERET WAKTU}

Deret waktu adalah serangkaian observasi terhadap suatu variabel yang diambil secara beruntun berdasarkan interval waktu yang tetap [5]. Kestasioneran data dapat diuji menggunakan Augmented Dickey-Fuller (ADF) dengan persamaan sebagai berikut [6]:

$$
\Delta Y_{t}=\beta_{0}+\phi Y_{t-1}+\sum_{i=1}^{p} \alpha_{i} \Delta Y_{t-i}+e_{t}
$$

dengan statistik uji sebagai berikut:

$$
A D F_{\text {hitung }}=\frac{\hat{\phi}}{S E(\hat{\phi})}
$$

dimana $S E(\hat{\phi})$ adalah standard error dari $\hat{\phi}$ dengan $\hat{\phi}$ dapat diestimasi menggunakan metode kuadrat terkecil dengan rumus sebagai berikut:

$$
\begin{gathered}
\hat{\phi}=\frac{\sum_{t=2}^{n}\left(\Delta Y_{t}-\Delta \bar{Y}_{t}\right)\left(Y_{t-1}-\bar{Y}_{t-1}\right)}{\sum_{t=2}^{n}\left(Y_{t-1}-\bar{Y}_{t-1}\right)^{2}} \\
S E(\hat{\phi})=\sqrt{\frac{\hat{\sigma}^{2}}{\sum_{t}^{n}\left(Y_{t-1}-\bar{Y}_{t-1}\right)^{2}}}
\end{gathered}
$$

dengan,

$$
\hat{\sigma}^{2}=\frac{\sum_{t=2}^{n} \hat{e}_{t}^{2}}{n-\beta}
$$

dimana $\hat{\sigma}^{2}$ adalah penduga varian residual $n$ adalah jumlah pengamatan dan $\beta$ adalah jumlah parameter yang diestimasi. Hipotesis yang digunakan untuk uji ADF adalah sebagai berikut:

$H_{0}$ : terdapat akar unit atau data tidak stasioner

$H_{1}$ : tidak terdapat akar unit atau data stasioner

dimana $H_{0}$ ditolak jika nilai mutlak ADF hitung > nilai kritis ADF atau nilai probabilitas $\mathrm{ADF}<$ tingkat signifikansi yang ditentukan, sehingga data dikatakan stasioner.

Model deret waktu univariat terdiri dari beberapa model, salah satunya yaitu Autoregressive (AR) yang dapat dikembangkan menjadi model Vector Autoregressive (VAR). Model VAR merupakan model deret waktu multivariat yang menggunakan lebih dari satu variabel di dalam model. Model VAR dengan penambahan variabel eksogen di dalam model dapat dikembangkan menjadi model Vector Autoregressive Exogenous (VARX).

\section{MODEL VECTOR AUTOREGRESSIVE EXOGENOUS}

Model Vector Autoregressive Exogenous (VARX) merupakan model deret waktu yang menggunakan lebih dari satu variabel endogen dengan penambahan variabel eksogen di dalam model. Variabel eksogen dapat juga disebut sebagai variabel independen sedangkan variabel endogen dapat juga disebut sebagai variabel dependen. Bentuk umum model VARX sebagai berikut [7]:

$$
\mathbf{Z}_{t}=\boldsymbol{a}+\boldsymbol{\phi}_{1} \mathbf{Z}_{t-1}+\cdots+\boldsymbol{\phi}_{p} \mathbf{Z}_{t-p}+\boldsymbol{\theta}_{1} \mathbf{X}_{t-1}+\cdots+\boldsymbol{\theta}_{q} \mathbf{X}_{t-q}+\boldsymbol{e}_{t}
$$

Persamaan (2) dapat dituliskan dalam matriks berikut:

$$
\left[\begin{array}{c}
Z_{1 t} \\
Z_{2 t} \\
\vdots \\
Z_{K t}
\end{array}\right]=\left[\begin{array}{c}
a_{1} \\
a_{2} \\
\vdots \\
a_{K}
\end{array}\right]+\left[\begin{array}{cccc}
\phi_{11(1)} & \phi_{12(1)} & \cdots & \phi_{1 k(1)} \\
\phi_{21(1)} & \phi_{22(1)} & \cdots & \phi_{2 k(1)} \\
\vdots & \vdots & \cdots & \vdots \\
\phi_{K 1(1)} & \phi_{K 2(1)} & \cdots & \phi_{K K(1)}
\end{array}\right]\left[\begin{array}{c}
Z_{1 t-1} \\
Z_{2 t-1} \\
\vdots \\
Z_{K t-1}
\end{array}\right]+\ldots+\left[\begin{array}{cccc}
\phi_{11(p)} & \phi_{12(p)} & \cdots & \phi_{1 k(p)} \\
\phi_{21(p)} & \phi_{22(p)} & \cdots & \phi_{2 k(p)} \\
\vdots & \vdots & \cdots & \vdots \\
\phi_{K 1(p)} & \phi_{K 2(p)} & \cdots & \phi_{K K(p)}
\end{array}\right]\left[\begin{array}{c}
Z_{1 t-p} \\
Z_{2 t-p} \\
\vdots \\
Z_{K t-p}
\end{array}\right]+
$$




$$
\left[\begin{array}{cccc}
\theta_{11(1)} & \theta_{12(1)} & \cdots & \theta_{1 T(1)} \\
\theta_{21(1)} & \theta_{22(1)} & \cdots & \theta_{2 T(1)} \\
\vdots & \vdots & \cdots & \vdots \\
\theta_{T 1(1)} & \theta_{T 2(1)} & \cdots & \theta_{T T(1)}
\end{array}\right]\left[\begin{array}{c}
X_{1 t-1} \\
X_{2 t-1} \\
\vdots \\
X_{T t-1}
\end{array}\right]+\ldots+\left[\begin{array}{cccc}
\theta_{11(q)} & \theta_{12(q)} & \cdots & \theta_{1 T(q)} \\
\theta_{21(q)} & \theta_{22(q)} & \cdots & \theta_{2 T(q)} \\
\vdots & \vdots & \cdots & \vdots \\
\theta_{T 1(q)} & \theta_{T 2(q)} & \cdots & \theta_{T T(q)}
\end{array}\right]\left[\begin{array}{c}
X_{1 t-q} \\
X_{2 t-q} \\
\vdots \\
X_{T t-q}
\end{array}\right]+\left[\begin{array}{c}
e_{1 t} \\
e_{2 t} \\
\vdots \\
e_{K t}
\end{array}\right]
$$

dengan,

$Z_{j t} \quad=$ Data variabel endogen ke $j$ pada waktu ke $t$ dengan $j=1,2, \ldots, K$ dan $t=1,2, \ldots, n$

$Z_{j t-i}=$ Data variabel endogen ke $j$ pada waktu ke $t$-i dengan $j=1,2, \ldots, K ; t=1,2, \ldots, n$ dan

$$
i=1,2, \ldots, p
$$

$a_{j} \quad=$ Konstanta persamaan variabel endogen ke $j$ dengan $j=1,2, \ldots, K$

$\phi_{j j(i)}=$ Koefisien parameter persamaan variabel endogen ke $j$ untuk variabel ke $j$ pada lag $i$ dengan $i=1,2, \ldots, p$

$\theta_{m m(i)}=$ Koefisien parameter persamaan variabel eksogen ke $m$ untuk variabel ke $m$ pada lag $i$ dengan $i=1,2, \ldots, q$

$X_{m t-i}=$ Data variabel eksogen ke $m$ pada waktu ke $t$-i dengan $m=1,2, \ldots, T ; t=1,2, \ldots, n$ dan $i=1,2, \ldots, q$

$\mathrm{e}_{j t} \quad=$ Residual variabel endogen ke $j$ pada waktu ke $t$ dengan $j=1,2, \ldots, K$ dan $t=1,2, \ldots, n$

Penentuan lag optimal pada model $\operatorname{VARX}(p, q)$ digunakan untuk menentukan panjang lag dalam menentukan orde $p$ dari $\operatorname{VAR}(p)$ dan kemudian menentukan orde $q$ dari X model VARX. Penentuan lag optimal dapat menggunakan Aikake Information Criterion (AIC) dirumuskan dengan persamaan berikut [5]:

$$
\operatorname{AIC}(p)=\ln \left(\left|\widehat{\Sigma}_{p}\right|\right)+\frac{2 m^{2} h}{n}
$$

dengan $\left|\widehat{\Sigma}_{p}\right|$ adalah determinan matriks kovarian residual untuk model $\operatorname{VAR}(p), \mathrm{n}$ adalah banyaknya pengamatan, $h$ adalah panjang lag dan $m$ adalah banyaknya variabel endogen dalam model. Lag yang terpilih sebagai orde model $\operatorname{VAR}(p)$ adalah lag yang mempunyai nilai AIC terkecil.

Estimasi parameter model VARX menggunakan metode kuadrat terkecil dengan prinsip meminimumkan jumlah kuadrar galat. Persamaan (2) dengan $\mathrm{n}$ pengamatan, dapat ditulis dalam bentuk linier sebagai berikut:

dimana,

$$
\mathbf{Y}=\mathbf{A} \boldsymbol{\beta}+\boldsymbol{\varepsilon}
$$

$$
\mathbf{Y}=\left[\begin{array}{c}
Z_{1} \\
Z_{2} \\
\vdots \\
Z_{n}
\end{array}\right]_{(n \times 1)} ; \mathbf{A}=\left[\begin{array}{ccccccc}
1 & \mathrm{Z}_{1-1} & \cdots & \mathrm{Z}_{1-p} & \mathrm{X}_{1-1} & \cdots & \mathrm{X}_{1-q} \\
1 & \mathrm{Z}_{2-1} & \cdots & \mathrm{Z}_{2-p} & \mathrm{X}_{2-1} & \cdots & \mathrm{X}_{2-q} \\
\vdots & \vdots & \ddots & \vdots & \vdots & \ddots & \vdots \\
1 & \mathrm{Z}_{n-1} & \cdots & \mathrm{Z}_{n-p} & \mathrm{X}_{n-1} & \cdots & \mathrm{X}_{n-q}
\end{array}\right]_{(n \times(p+q+1))} \quad ; \boldsymbol{\varepsilon}=\left[\begin{array}{c}
\varepsilon_{1} \\
\varepsilon_{2} \\
\vdots \\
\varepsilon_{n}
\end{array}\right]_{(n \times 1)} ; \boldsymbol{\beta}=\left[\begin{array}{c}
a \\
\phi_{1} \\
\vdots \\
\phi_{p} \\
\theta_{1} \\
\vdots \\
\theta_{q}
\end{array}\right]_{(p+q+1) \times 1)}
$$

dengan nilai estimasi parameter menggunakan metode kuadrat terkecil sebagai berikut:

$$
\hat{\boldsymbol{\beta}}=\left(\mathbf{A}^{\prime} \mathbf{A}\right)^{-1} \mathbf{A}^{\prime} \mathbf{Y}
$$

Model VARX yang dibentuk dari hasil estimasi parameter selanjutnya diuji signifikansi parameter. Pengujian signifikansi parameter endogen menggunakan uji t statistik dengan rumus: 


$$
t_{\text {hitung }}=\frac{\widehat{\phi}_{i}}{S E\left(\hat{\phi}_{i}\right)}
$$

dan pengujian signifikansi parameter eksogen dengan rumus:

$$
t_{\text {hitung }}=\frac{\hat{\theta}_{j}}{S E\left(\hat{\theta}_{j}\right)}
$$

dimana $n$ adalah jumlah pengamatan dan $m$ adalah jumlah variabel endogen. Dengan kriteria uji jika nilai $\left|t_{\text {hitung }}\right|>t_{\alpha / 2,(n-m)}$ atau $p$-value $<\alpha$ maka parameter berpengaruh pada model.

Pada pemodelan VARX asumsi yang sebaiknya dipenuhi yaitu residual white noise dan berdistribusi normal multivariat. Uji yang dapat digunakan dalam asumsi residual white noise adalah uji portmanteau dengan Statistik uji yang digunakan sebagai berikut [8]:

$$
\begin{gathered}
Q_{h}=n \sum_{j=1}^{p} \operatorname{tr}\left(\hat{\mathbf{c}}_{\mathbf{j}}^{\prime} \hat{\mathbf{c}}_{\mathbf{0}}^{-1} \hat{\mathbf{c}}_{\mathbf{j}} \hat{\mathbf{c}}_{\mathbf{0}}^{-1}\right) \\
\hat{\mathbf{c}}_{\mathbf{j}}=\frac{1}{\mathrm{n}} \sum_{\mathrm{t}=\mathbf{j}+1}^{\mathrm{n}} \hat{\mathbf{u}}_{\mathbf{t}} \hat{\mathbf{u}}_{\mathbf{t}-\mathbf{j}}^{\prime}
\end{gathered}
$$

dimana,

$\hat{\mathbf{c}}_{\mathbf{j}} \quad=$ matriks penduga autokovarians dari residual $\hat{\mathbf{u}}_{\mathbf{t}}$

$\hat{\mathbf{c}}_{\mathbf{0}} \quad=$ matiks $\widehat{\mathbf{c}}_{\mathbf{j}}$ ketika $\mathbf{j}=0$

$\mathrm{n} \quad=$ jumlah sampel

dengan kriteria uji jika $Q_{h} \geq \chi_{\alpha ;\left(m^{2} h-n^{*}\right)}^{2}$ atau probability $<\alpha$ maka residual tidak memenuhi asumsi white noise dengan $h$ adalah panjang lag, $m$ adalah jumlah variabel endogen dan $n^{*}$ adalah jumlah koefisien selain konstanta yang diamati. Uji asumsi residual normal multivariat dapat dilihat dari grafik Q-Q plot residual dan juga dapat menggunakan uji koefisien korelasi [9]. dengan statistik uji yang digunakan yaitu:

$$
r_{Q}=\frac{\sum_{t=1}^{n}\left(d_{t}^{2}-\bar{d}^{2}\right)\left(q_{t}-\bar{q}\right)}{\sqrt{\sum_{t=1}^{n}\left(d_{t}^{2}-\bar{d}^{2}\right)^{2} \sqrt{\sum_{t=1}^{n}\left(q_{t}-\bar{q}\right)^{2}}}}
$$

dengan rumus jarak mahalanobis yaitu:

$$
d_{i}^{2}=\left(y_{i}-\bar{y}\right)^{\prime} S^{-1}\left(y_{i}-\bar{y}\right)
$$

dan rumus nilai quantile chi square yaitu:

$$
q_{t}=\chi_{p}^{2}, \frac{i-0,5}{n}
$$

dengan $y_{i}$ adalah vektor data ke- $i$ dimana $i=1,2, \ldots, p, \bar{y}$ adalah vektor rata-rata data, $S^{-1}$ merupakan matriks kovarian data, $n$ adalah jumlah pengamatan, $r_{Q}$ merupakan nilai korelasi antara nilai quantile chi square dan jarak mahalanobis dari tiap variabel dan $r_{Q(\alpha, n)}$ adalah nilai tabel kritis uji koefisien korelasi Q-Q plot. Jiika $r_{Q}<r_{Q(\alpha, n)}$ maka residual tidak berdistribusi normal multivariat.

\section{KETEPATAN PREDIKSI}

Hasil dari pemodelan VARX dilakukan pengecekan keakuratan prediksi dengan Mean Absolute Percentage Error (MAPE). Dengan rumus MAPE sebagai berikut :

$$
M A P E=\frac{\sum_{t=1}^{n}\left|\frac{\hat{Y}_{t}-Y_{t}}{Y_{t}}\right|}{n} \times 100 \%
$$


dimana $Y_{t}$ adalah nilai aktual data, $\hat{Y}_{t}$ adalah nilai prediksi data dan $n$ adalah jumlah data prediksi model VARX. Hasil prediksi dikatakan sangat baik jika nilai MAPE kurang dari 10\% dan jika nilai MAPE berkisar antara $10 \%$ sampai $20 \%$ maka hasil peramalan baik [10].

\section{PREDIKSI HASIL PRODUKSI KARET MODEL VARX}

Data penelitian yang digunakan merupakan data sekunder, yaitu data bulanan hasil produksi karet yang terdiri dari hasil produksi karet kering dan karet basah pada kebun Sintang dan data curah hujan pada daerah kebun. Periode data yang digunakan yaitu data in sample mulai Januari 2016 sampai Juni 2018 sedangkan data out sample mulai Juli 2018 sampai Desember 2018.

Pada proses pengujian stasioneritas digunakan uji Augmented Dickey-Fuller (ADF). Data dikatakan stasioner apabila nilai mutlak ADF hitung lebih besar dari nilai kritis pada $\alpha=5 \%$. Jika data tidak stasioner, maka data akan didifferencing lalu dilakukan pengujian stasioneritas kembali. Hasil uji stasioneritas data disajikan sebagai berikut:

Tabel 1 Uji Stasioneritas Data

\begin{tabular}{lrrrl}
\hline \multicolumn{1}{c}{ Variabel } & ADF & $\boldsymbol{\alpha}=5 \%$. & Prob & \multicolumn{1}{c}{ Keterangan } \\
\hline Karet Kering & $-4,963815$ & $-3,612199$ & 0,0029 & Stasioner \\
\hline Karet Basah & $-2,060049$ & $-3,574244$ & 0,5453 & Tidak Stasioner \\
\hline Curah Hujan & $-3,797938$ & $-3,574244$ & 0,0313 & Stasioner \\
\hline
\end{tabular}

Dari Tabel 1 dapat dilihat bahwa terdapat satu variabel yang tidak stasioner yaitu variabel karet basah, sehingga data pada variabel karet basah akan dilakukan differencing kemudian dilakukan pengujian stasioneritas kembali sehingga semua data stasioner.

Tabel 2 Uji Stasioneritas Data Differencing

\begin{tabular}{ccccc}
\hline Variabel & ADF & $\boldsymbol{\alpha}=5 \%$. & Prob & Keterangan \\
\hline dKaret Kering & $-3,756987$ & $-3,632896$ & 0,0394 & Stasioner \\
\hline dKaret Basah & $-5,264720$ & $-3,580623$ & 0,0011 & Stasioner \\
\hline dCurah Hujan & $-3,643310$ & $-3,612199$ & 0,0470 & Stasioner \\
\hline
\end{tabular}

\section{Identifikasi Model VARX}

Identifikasi model VARX dilakukan dengan menentukan orde $p$ dari $\operatorname{VAR}(p)$ kemudian menentukan orde $q$ dari X dengan menggunakan plot Matrix Partial Autocorrelation Function (MPACF) dan nilai minimum dari Akaike's Information Criterion (AIC) sebagai berikut:

\begin{tabular}{|c|c|c|c|c|c|c|c|c|c|c|}
\hline \multicolumn{11}{|c|}{ Schematic Representation of Partial Autocorrelations: } \\
\hline Name/Lag & 1 & 2 & 3 & 4 & 5 & 6 & 7 & 8 & 9 & 10 \\
\hline $\begin{array}{c}\text { KK } \\
\text { KB }\end{array}$ & - . & $\because$ & $\because$ & - & $\because$ & $\because$ & $\because$ & . & $\because$ & . \\
\hline
\end{tabular}

Gambar 1 Plot MPACF Orde $p$

Pada Gambar 1 dapat dilihat bahwa pada plot MPACF orde $p$ lag yang muncul yaitu pada lag 1,4 dan 6 dengan nilai AIC terkecil terdapat pada lag 1 yaitu 979,6857 sehingga orde $p$ adalah 1 . Untuk penentuan orde $q$ selanjutnya sebagai berikut:

\begin{tabular}{|c|c|c|c|c|c|c|c|c|}
\hline \multicolumn{9}{|c|}{ Schematic Representation of Partial Autocorrelations } \\
\hline Name/Lag & 1 & 2 & 3 & 4 & 5 & 6 & 7 & $\mathbf{B}$ \\
\hline KK & $-\ldots$ & $\ldots$ & $\ldots$ & $\ldots$ & $\ldots$ & $\ldots$ & $\ldots$ & $\ldots$ \\
\hline KB & $\ldots$ & $\ldots$ & $\ldots$ & $\ldots$ & $\ldots$ & $\ldots$ & $\ldots$ & $\ldots$ \\
\hline CH & $\ldots-$ & $\ldots$ & $\ldots$ & $\ldots$ & $\ldots$ & $\ldots$ & $\ldots$ & $\cdots$ \\
\hline
\end{tabular}

Gambar 2 Plot MPACF Orde $q$ 
Pada Gambar 2 dapat dilihat bahwa pada plot MPACF orde $p$ lag yang muncul yaitu pada lag 1 dengan nilai AIC terkecil untuk orde $q$ terdapat pada lag 1 yaitu 1260,641 sehingga orde $q$ adalah 1 . Dengan demikian maka model VARX yang terbentuk adalah VARX $(1,1)$.

Model VARX yang telah diperoleh selanjutnya dilakukan estimasi parameter menggunakan metode kuadrat terkecil sebagai berikut:

Tabel 3 Estimasi Parameter VARX

\begin{tabular}{lccc}
\hline & Parameter & Estimasi & Variabel \\
\hline \multirow{3}{*}{ Karet Kering } & $a_{1}$ & $-686,186$ & Konstan \\
\cline { 2 - 4 } & $\phi_{11(1)}$ & $-0,62552$ & d_Karet Kering \\
\cline { 2 - 4 } & $\phi_{12(1)}$ & 0,08168 & d_Karet Basah \\
\hline$\theta_{11(1)}$ & 0,79803 & d_Curah Hujan \\
\hline Karet Basah & $a_{2}$ & 1660,423 & Konstan \\
\cline { 2 - 4 } & $\phi_{21(1)}$ & $-0,83032$ & d_Karet Kering \\
\hline$\phi_{22(1)}$ & 0,11876 & d_Karet Basah \\
\hline$\theta_{21(1)}$ & $-5,8798$ & d_Curah Hujan \\
\hline
\end{tabular}

Hasil dari pemodelan VARX $(1,1)$ untuk variabel produksi karet kering $\left(\mathrm{Z}_{1 t}\right)$ dan produksi karet basah $\left(\mathrm{Z}_{2 t}\right)$ diperoleh persamaan sebagai berikut:

$$
\begin{aligned}
& Z_{1 t}=-686,186-0,62552 Z_{1 t-1}+0,08168 Z_{2 t-1}+0,79803 X_{1 t-1} \\
& Z_{2 t}=1660,423-0,83032 Z_{1 t-1}+0,11876 Z_{2 t-1}-5,8798 X_{1 t-1}
\end{aligned}
$$

dimana $Z_{1 t}$ adalah hasil produksi karet kering pada waktu ke $t, Z_{1 t-1}$ adalah hasil produksi karet kering pada waktu ke $t$-1, kemudian $Z_{2 t}$ adalah data hasil produksi karet basah pada waktu ke $t, Z_{2 t-1}$ adalah data hasil produksi karet basah pada waktu ke $t-1$ dan $X_{1 t-1}$ adalah curah hujan pada waktu ke $t-1$.

Hasil estimasi parameter diuji signifikan parameter dimana jika nilai $p$-value $<0,05$ maka parameter berpengaruh signifikan terhadap model.

Tabel 4 Uji Signifikansi Parameter

\begin{tabular}{cccc}
\hline Parameter & t-hitung & Probabilitas & Keterangan \\
\hline $\boldsymbol{\phi}_{\mathbf{1 1}(\mathbf{1})}$ & $-2,26$ & 0,0329 & Parameter signifikan \\
\hline $\boldsymbol{\phi}_{\mathbf{1 2}(\mathbf{1})}$ & 0,62 & 0,5440 & Parameter tidak signifikan \\
\hline $\boldsymbol{\theta}_{\mathbf{1 1}(\mathbf{1})}$ & 0,14 & 0,8923 & Parameter tidak signifikan \\
\hline $\boldsymbol{\phi}_{\mathbf{2 1}(\mathbf{1})}$ & $-1,21$ & 0,2391 & Parameter tidak signifikan \\
\hline $\boldsymbol{\phi}_{\mathbf{2 2}(\mathbf{1})}$ & 0,36 & 0,7224 & Parameter tidak signifikan \\
\hline $\boldsymbol{\theta}_{\mathbf{2 1}(\mathbf{1})}$ & $-0,40$ & 0,6892 & Parameter tidak signifikan
\end{tabular}

Pada Tabel 4 dapat dilihat bahwa hanya terdapat satu parameter yang signifikan berpengaruh terhadap model yaitu parameter $\phi_{11(1)}$. Walaupun tidak terdapat parameter yang signifikan, peramalan tetap dapat dilanjutkan karena dalam peramalan hal yang paling penting adalah kemampuan model VARX dalam meramalkan data [4].

\section{Uji Asumsi Residual}

Uji asumsi residual white noise bertujuan untuk mengetahui korelasi antar vektor residual dari model $\operatorname{VARX}(1,1)$ yang telah terbentuk. Dengan plot residual sebagai berikut:
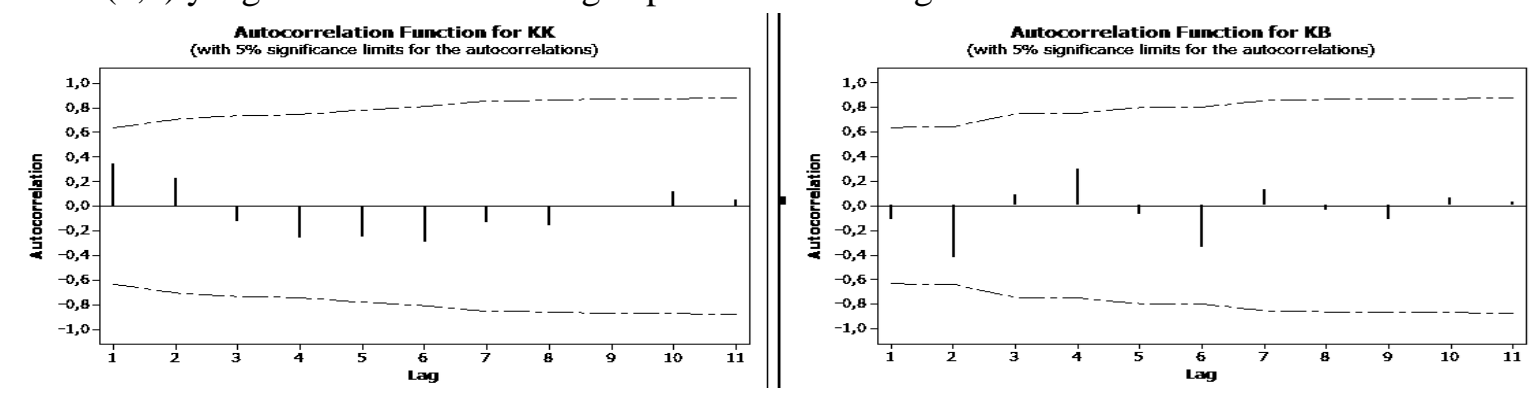

Gambar 3 Plot Residual White noise 
Berdasarkan pada Gambar 3 dapat dilihat bahwa setiap lag tidak signifikan artinya tidak ada korelasi residual dan nilai probabilitas pada uji portmanteau untuk setiap lag lebih besar dari 0,05 atau $p$-value $>0,05$ maka dapat disimpulkan bahwa residual memenuhi asumsi white noise. Langkah selanjutnya yaitu uji asumsi normal multivariat menggunakan uji koefisien korelasi Q-Q plot yang disajikan sebagai berikut:

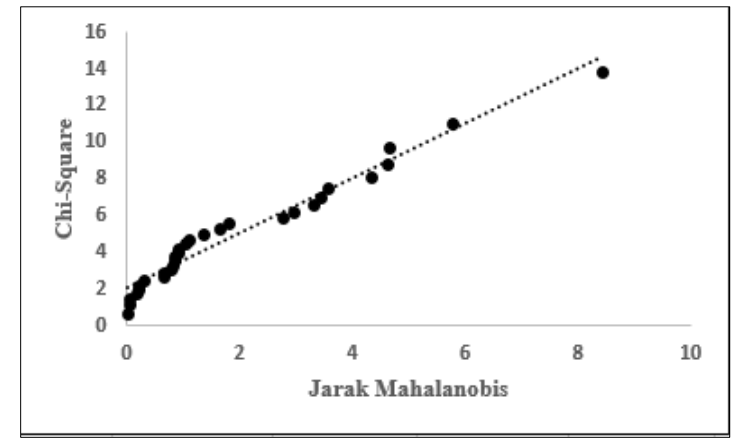

Gambar 4 Q-Q Plot Normal Multivariat

dengan hasil statistik uji $r_{Q}$ yang diperoleh yaitu 0,98048 dengan nilai tabel kritis uji koefisien korelasi $r_{Q(0.05 ; 30)}$ yaitu 0,9652 , dimana $0,98048>0,9652$ sehingga $H_{0}$ diterima artinya residual dari model VARX $(1,1)$ berdistribusi normal multivariat. Q-Q plot uji asumsi residual normal multivariat

\section{Prediksi Model VARX}

Prediksi hasil produksi karet kering dan karet basah untuk periode Juli 2018 sampai Desember 2018 menghasilkan model akhir untuk VARX $(1,1)$ dengan hasil prediksi produksi karet kering dan karet basah disajikan sebagai berikut:

Tabel 6 Hasil Prediksi Produksi Karet PTPN XIII

\begin{tabular}{lcccc}
\hline \multirow{3}{*}{ Periode } & \multicolumn{2}{c}{ Data Aktual } & \multicolumn{2}{c}{ Data Ramalan } \\
\cline { 2 - 5 } & $\begin{array}{c}\text { Karet Kering } \\
(\mathrm{kg})\end{array}$ & $\begin{array}{c}\text { Karet Basah } \\
(\mathrm{kg})\end{array}$ & $\begin{array}{c}\text { Karet Kering } \\
(\mathrm{kg})\end{array}$ & $\begin{array}{c}\text { Karet Basah } \\
(\mathrm{kg})\end{array}$ \\
\hline Juli & 17305 & 54068 & 14311,35 & 41273,04 \\
\hline Agustus & 17107 & 53165 & 14524,39 & 53853,17 \\
\hline September & 13786 & 43010 & 16431,17 & 55175,40 \\
\hline Oktober & 12657 & 39353 & 14394,95 & 45873,82 \\
\hline November & 15996 & 49754 & 12637,28 & 39608,55 \\
\hline Desember & 13719 & 47469 & 14000,29 & 50396,39 \\
\hline
\end{tabular}

Dengan nilai MAPE untuk hasil prediksi data out sample variabel produksi karet basah dan karet kering. Hasil perhitungan nilai MAPE disajikan sebagai berikut:

\begin{tabular}{cc}
\multicolumn{2}{c}{ Tabel 7 Nilai MAPE Model VARX } \\
\hline Variabel & MAPE \\
\hline Karet Kering & 14,727037 \\
\hline Karet Basah & 16,062047 \\
\hline
\end{tabular}

Dapat dilihat bahwa nilai mape untuk karet kering dan karet basah menghasilkan nilai prediksi kurang dari $20 \%$ maka dapat disimpulkan bahwa model VARX $(1,1)$ untuk variabel karet kering dan karet basah memiliki kemampuan prediksi yang baik.

\section{PENUTUP}

Berdasarkan hasil penelitian yang dibahas pada bab sebelumnya, pemodelan dan prediksi hasil produksi karet kering dan karet basah dengan model VARX dapat diambil kesimpulan yaitu 
1. Model VARX yang terbentuk untuk data hasil produksi karet kering $\left(\mathrm{Z}_{1 t}\right)$ dan karet basah $\left(\mathrm{Z}_{2 t}\right)$ adalah model VARX $(1,1)$. Bentuk persamaan dari model $\operatorname{VARX}(1,1)$ yaitu $Z_{1 t}=-686,186-$ $0,62552 Z_{1 t-1}+0,08168 Z_{2 t-1}+0,79803 X_{1 t-1} \quad$ dan $\quad Z_{2 t}=1660,423-0,83032 Z_{1 t-1}+$ $0,11876 Z_{2 t-1}-5,8798 X_{1 t-1}$.

2. Hasil prediksi data hasil produksi karet kering dan karet basah dengan menggunakan model VARX $(1,1)$. Nilai MAPE out sample, yaitu masing-masing sebesar 14,73\% dan 16,06\% sehingga model VARX memiliki kemampuan prediksi yang baik.

\section{DAFTAR PUSTAKA}

[1]. Setyawan, E., Subantoro, R., dan Prabowo, R. Analisis Faktor Yang Berpengaruh Terhadap Produksi Karet di PT Perkebunan Nusantara IX Kebun Sukamangli Kabupaten Kendal. Jurnal Ilmu Pertanian. 2016;12(1):32-44.

[2]. Sinaga, D.M., Irsal, dan Mawarni, L. Pengaruh Curah Hujan dan Hari Hujan Terhadap Produksi Karet Berumur 7, 10 dan 13 Tahun di Kebun Sei Baleh Estate PT. Bakrie Sumatera Plantations, Tbk. Jurnal Agroekoteknologi. 2017;5(1):93-102.

[3]. Hargianto, A., Rahayu, E.S., dan Darsono. Analisis Peramalan Produksi Karet Di PT Perkebunan Nusantara IX (Persero) Kebun Batujamus Kabupaten Karanganyar. Agribusiness Review. 2013;1(1):45-64.

[4]. Rosyidah, H., Rahmawati, R., dan Prahutama, A. Pemodelan Vector Autoregressive X (VARX) Untuk Meramalkan Jumlah uang Beredar di Indonesia. Jurnal Gaussian. 2017;6(3): 333-343.

[5]. Wei, W.W.S. Time Series Analysis Univariate and Multivariate Methods. Second Edition. Pearson Education, Inc. USA;2006

[6]. Gujarati, D.N. Basic Econometrics. Ed ke-4. McGraw Hill. New York;2003.

[7]. Ocampo, S. and Rodriguez, N. An Introductory Review of a Structural VAR-X Estimation and Applications. Borradores de Economia. 2011;686.

[8]. Lutkepohl, H dan Kratzig, M. Applied Time Series Econometrics. Cambridge University Press. New York;2004.

[9]. Johnson, R.A.,Winchern, D.W. Applied Multivariate Statistical Analysis. 6th Edition. Pearson Prentice Hall. New Jersey;2007.

[10]. Montgomery, D.C., Jennings, C.L., dan Kuhlaci, M. Introduction to Time Series Analysis and Forecasting. John Wiley \& Sons. New Jersey;2008.

ROSELLA ALIFA EL VINIE : Jurusan Matematika FMIPA UNTAN, Pontianak elrosella@student.untan.ac.id

SHANTIKA MARTHA $\quad$ : Jurusan Matematika FMIPA UNTAN, Pontianak shantika.martha@math.untan.ac.id

SETYO WIRA RIZKI $\quad$ : Jurusan Matematika FMIPA UNTAN, Pontianak setyo.wirarizki@math.untan.ac.id 